\title{
Area-level socioeconomic characteristics and incidence of metabolic syndrome: a prospective cohort study
}

Anh D Ngo ${ }^{1,6^{*}}$, Catherine Paquet ${ }^{1,2}$, Natasha J Howard ${ }^{1}$, Neil T Coffee ${ }^{1}$, Robert Adams ${ }^{4}$, Anne Taylor ${ }^{3}$ and Mark Daniel ${ }^{1,5}$

\begin{abstract}
Background: The evidence linking socioeconomic environments and metabolic syndrome (MetS) has primarily been based on cross-sectional studies. This study prospectively examined the relationships between area-level socioeconomic position (SEP) and the incidence of MetS.
\end{abstract}

Methods: A prospective cohort study design was employed involving 1,877 men and women aged 18+ living in metropolitan Adelaide, Australia, all free of MetS at baseline. Area-level SEP measures, derived from Census data, included proportion of residents completing a university education, and median household weekly income. MetS, defined according to International Diabetes Federation, was ascertained after an average of 3.6 years follow up. Associations between each area-level SEP measure and incident MetS were examined by Poisson regression Generalised Estimating Equations models. Interaction between area- and individual-level SEP variables was also tested.

Results: A total of 156 men (18.7\%) and 153 women (13.1\%) developed MetS. Each percentage increase in the proportion of residents with a university education corresponded to a $2 \%$ lower risk of developing MetS (age and sex-adjusted incidence risk ratio $(R R)=0.98 ; 95 \%$ confidence interval $(C l)=0.97-0.99)$. This association persisted after adjustment for individual-level income, education, and health behaviours. There was no significant association between area-level income and incident MetS overall. For the high income participants, however, a one standard deviation increase in median household weekly income was associated with a 29\% higher risk of developing MetS (Adjusted $\mathrm{RR}=1.29 ; 95 \% \mathrm{Cl}=1.04-1.60$ ).

Conclusions: While area-level education was independently and inversely associated with the risk of developing MetS, the association between area-level income and the MetS incidence was modified by individual-level income.

Keywords: Metabolic syndrome, Incidence, Socioeconomic status, Income, Education, Cohort study, Residence characteristics

\footnotetext{
* Correspondence: Anh.Ngo@unisa.edu.au

${ }^{1}$ Social Epidemiology and Evaluation Research Group, Sansom Institute for

Health Research, and School of Population Health, University of South

Australia, Adelaide 5001, Australia

${ }^{6}$ Social Epidemiology and Evaluation Research Group, Sansom Institute for

Health Research, and School of Population Health, University of South

Australia, P4-18F, Playford Building, City East Campus, Adelaide 5000,

Australia

Full list of author information is available at the end of the article
}

\section{Biomed Central}

(c) 2013 Ngo et al.; licensee BioMed Central Ltd. This is an Open Access article distributed under the terms of the Creative Commons Attribution License (http://creativecommons.org/licenses/by/2.0), which permits unrestricted use, distribution, and reproduction in any medium, provided the original work is properly cited. 


\section{Background}

A growing literature has documented the relationship between individual and residential area (often referred to as "neighbourhood") socioeconomic position (SEP) with a wide range of health outcomes, including cardiometabolic diseases (i.e., cardiovascular diseases and type 2 diabetes). Low neighbourhood SEP, for example, has been found to be associated with an increased incidence of ischaemic stroke [1], incidence of coronary heart disease (CHD) [2], and incidence of type 2 diabetes [3,4]. Although the underlying mechanisms involved in this relationship are not entirely elucidated [5-7], a growing body of evidence demonstrates that socioeconomic factors influence cardiometabolic health outcomes through shaping health related behaviours and psychological antecedents, and subsequently predicting biological risk factors [8-10]. Available research also indicates that area-level socioeconomic conditions can operate independently or interactively with individual-level SEP to determine whether a predisposition to developing cardiometabolic diseases is realised $[11,12]$.

Metabolic syndrome (MetS) - a clustering of disturbed glucose and insulin metabolism, obesity or abdominal adiposity, dyslipidaemia, and hypertension, is an important risk factor for cardiometabolic diseases. There is relatively well-established evidence showing an inverse association between individual-level SEP and prevalence or incidence of MetS [13-26] or its components [8,27-35]. Also, a substantial body of literature has demonstrated that living in socioeconomically disadvantaged areas is associated with an increased prevalence or incidence of MetS components: prevalence of type 2 diabetes or insulin resistance [4,36-38], high blood pressure [36,38-43], and larger waist [41,44], and incidence of type 2 diabetes [3,4]. Some studies have also reported evidence of interaction between area- and individual-level SEP characteristics with associations either stronger or only present in low SEP individuals [12]. For example, associations between statelevel income inequality and cardiometabolic risk factors (e.g., body mass index (BMI), hypertension, and sedentarism) have been found to be stronger in low income individuals [43]. However, the role of area-level SEP in shaping the distribution and development of MetS - a stronger risk marker of cardiometabolic disease has been infrequently examined. A recent review reported that out of 56 studies evaluating the influence of the socioeconomic environment on cardiometabolic risk factors, only two considered MetS as the outcome in analysis [12].

Four cross-sectional studies have evaluated the relationships between area-level socioeconomic conditions on prevalent MetS (or a cluster of the MetS components). The results of these studies have consistently shown an inverse association [45-48], but in one study [46], the strength of associations varied according to individuallevel income and education. Being cross-sectional, these studies could not assess the predictive capacity of arealevel SEP in relation to the development of MetS over time. Furthermore, available studies used a composite index or score to rate area-level SEP. While this method allowed for the evaluation of multiple features of arealevel SES, it did not allow for the disentanglement of independent effects pertaining to specific features of area-level SEP on incident MetS. Thus, there is a need to conduct a longitudinal study to evaluate relationships between specific characteristics of area-level SEP and the development of MetS.

Characteristics of individual- and area-level SEP are interrelated. Individual SEP may influence the area where one chooses to reside, while area-level socioeconomic conditions both reflect and shape social and built environments of the residential area, and potentially affect the socioeconomic attainment of residents via educational and occupational opportunities [49]. Given these interrelationships, attention is increasingly shifting to disentangling the independent and/or joint effect of individual SEP and residential area socioeconomic conditions on cardiometabolic outcomes $[12,43,45]$. To our knowledge, however, no studies have empirically tested whether arealevel and individual-level SEP factors independently or interactively influence the development of MetS.

The purpose of this study was to go beyond individual cardiometabolic risks in examining the development of MetS as a cluster of risks and a stronger predictor of cardiometabolic disease in relation to area-level SEP factors. It sought to expand the literature by examining the influence of area-level SEP on incident MetS and exploring if this influence is independent of or differed by individual-level SEP. The aims of the study were: (i) to estimate the incidence of MetS in a population-based cohort; (ii) to examine the relationships between specific features of area-level SEP and incident MetS; and (iii) to determine whether these relationships were modified by individual-level measures of SEP. Hypotheses were: (i) area-level SEP characteristics would be inversely associated with the development of MetS; (ii) these associations would be either stronger or present only in low SEP individuals.

\section{Methods}

\section{Study population}

This study was conducted through the Place and Metabolic Syndrome (PAMS) project, a research initiative that aims to evaluate the relationships between localarea social and built environmental factors and cardiometabolic health. The project draws on the North West Adelaide Health Study (NWAHS), a population-based prospective cohort study designed to provide longitudinal self-reported and clinically measured data on a number of chronic health outcomes and disease risk 
factors [50]. Data collection was based in the northern and western regions of metropolitan Adelaide, the capital city of South Australia (SA). The study region accounts for $38 \%$ of the Adelaide metropolitan population and $28 \%$ of the state population [51]. Furthermore, the north-west region of Adelaide has been identified as having high proportions of low income families and the lowest full-time secondary school participation rates [52]. The eligible population included persons from households that, at study inception and time of baseline sampling, had a telephone with the corresponding number listed in the Electronic White Pages directory.

Baseline recruitment was carried out between 2000 and 2003. Telephone numbers of households in the study region listed in the Electronic White Pages directory were randomly selected. An invitation letter was sent to selected households followed within 10 days by a telephone call from trained health study recruiters. Initially, 8,213 residents aged 18 years or older from selected households were asked to participate in the study of whom 5,850 (71.2\%) completed a computerassisted telephone interview (CATI) (Additional file 1). Interview respondents were sent a questionnaire for selfreporting a number of chronic conditions and health risk factors (Additional file 2). Finally, consenting participants attended a biomedical examination that involved anthropometric measurements and blood draws to assay biochemical measures and determine cardiometabolic risk factors as well as MetS. At Wave 1, 4,056 participants $(49.4 \%$ of the eligible sample, and $69.4 \%$ of those who completed the CATI) completed the examination.

Two additional waves of data collection were undertaken; Wave 2 (2004-06) and Wave 3 (2008-10). One hundred participants died and 22 withdrew from the study between the first and second waves of data collection, leaving 3,943 participants eligible for Wave 2 participation (Additional file 3). Of these participants, 3,206 (81\%) attended a follow-up biomedical assessment. At each wave of data collection, based on residential address information, valid records were assigned a georeference to represent the participant's longitude and latitude. The population for the present study comprised of baseline-MetS free participants who completed biomedical assessments at Wave 1 and 2. Ethics approval was obtained from three Human Research Ethics Committees: the University of South Australia, Central Northern Adelaide Health Service and the South Australian Department of Health and Aging. Written informed consent was obtained from all participants prior to data collection.

\section{Metabolic syndrome}

MetS was defined, using the International Diabetes Foundation criteria [53], as abdominal obesity (waist circumference $\geq 94 \mathrm{~cm}$ for Europid men and $\geq 90 \mathrm{~cm}$ for
non-Europid men, and $\geq 80 \mathrm{~cm}$ for Europid and nonEuropid women) plus any two or more of the following four metabolic abnormalities: Hypertriglyceridemia $(\geq 1.7 \mathrm{mmol} / \mathrm{l})$ or specific treatment for this lipid abnormality; low high-density lipoprotein (HDL) cholesterol level ( $\leq 1.3 \mathrm{mmol}$ in women, $\leq 1.0 \mathrm{mmol}$ in men) or specific treatment for this lipid abnormality; elevated blood pressure $(\geq 130 / 85 \mathrm{~mm} \mathrm{Hg})$ or treatment of previously diagnosed hypertension; and hyperglycaemia (fasting plasma glucose $>6.1 \mathrm{mmol} / \mathrm{l}$ ) or previously diagnosed type 2 diabetes.

\section{Area-level socioeconomic position}

For this research, the spatial unit was the 2001 State Suburb (SSC), an Australian Bureau of Statistics (ABS) Census Geographic Unit [54] which approximates to administrative boundaries (i.e., suburbs) within urban areas. The use of State Suburbs to express environmental scale provides adequate numbers of participants within area-level units, in addition to reasonable between unit variability. The study region consisted of 154 State Suburbs, with a median population of 2,027 persons. A geographic information system (GIS) was utilised to assign each participant to a State Suburb based on the Wave 1 georeference. Area-level SEP data represented at the State Suburb were obtained from the 2001 ABS Population and Housing Census. Two measures were extracted for analysis: the proportion of residents 18 years or older who had completed a university degree, and median household weekly income (in Australian Dollars (AUD)).

\section{Covariates}

Covariates included in the analysis were measured at Wave 1. Individual-level SEP was represented in terms of self-reported education attainment (having a least a bachelor degree, or not) and gross annual household income classified as low (<20,000 AUD); middle (20,00060,000 AUD); and high (>60,000 AUD). These variables were also tested as potential effect modifiers of arealevel SEP measures. Other individual covariates included age (in years), gender (male vs. female), and cardiometabolic risk behaviours. Smoking status was classified as current, former, and non- smokers. Alcohol consumption was defined as at risk and not at risk drinkers according to national guidelines [55]. Male participants were considered "at risk" if they consumed more than six standard drinks on any one day, an average of more than four drinks per day, or more than 28 standard drinks over a week. Female participants were coded "at risk" if they consumed more than four standard drinks on any one day, an average of more than two drinks per day, or more than 14 standard drinks over a week. 
Health behaviours were ascertained from self-reported questions obtained from the ABS, National Health Survey Questionnaire and Guidelines [56]. The physical activity level was evaluated according to Metabolic Equivalence Tasks (METs) in hours per week [57] derived from the total amount and intensity of physical activity (walking, moderate and vigorous physical activity) carried out for sport, recreation or fitness within the last two weeks. Participants were assigned to either the sedentary, low, moderate, or high category if they achieved $\leq 100$ METs, 100 - $\leq 1600$ METs, $1600-\leq 3,200$ METs, and >3,200 METs, respectively (Additional file 4).

\section{Statistical analysis}

All analyses were performed with Stata version 11.0 [58]. Incident MetS was calculated by dividing the number of new cases by the number of individuals at risk. Descriptive statistics included frequency distributions for categorical variables (e.g., individual income and education), and determination of mean, median, and standard deviation for continuous variables (e.g., age, area-level income and education).

Associations between each area-level SEP characteristic and the incident of MetS were tested separately in four sequential statistical models. Poisson regression, conducted using Generalised Estimating Equation (GEE), was performed to compute incidence risk ratio (RR) and 95\% Confidence Interval (CI). In model 1 (base model), we examined the association between the outcome variable and each area-level SEP variable, adjusted for age and gender. In model 2, we added individual SEP variables (i.e., income and education). In model 3 (full model), we added behavioural variables (i.e., smoking, alcohol consumption, and physical activity). In model 4 , we added the other arealevel SEP variable to test the relative importance of one component of area-level SEP over the other in predicting the incident MetS. Two-way interaction terms between area- and individual-level SEP variables were assessed for statistical significance. Analyses stratified by individuallevel SEP were conducted when statistical evidence for an interactive effect $(p<0.05)$ was observed. To test if the association differed by gender, two-way interaction terms between area-level SEP characteristics and gender were also added to statistical models. GEE was used to account for the clustering of observations within spatial units (State Suburbs). This approach has been proposed to provide accurate estimates for the relationships between arealevel characteristics and individual-level health outcomes in multilevel studies $[59,60]$.

\section{Results}

\section{Sample description}

The sample available for the current analysis contained 2,586 participants, none of whom had MetS at baseline. At Wave 2, MetS status was determined for 1,991 participants (77\%). Due to missing data for one or more of independent variables or covariates, a further 114 participants were removed from analysis. As a result, the final sample contained 1,877 participants residing in 143 State Suburbs. The median number of participants per spatial unit was 10, ranging from 1 to 56. The average follow up time was 3.6 years, varying from 1.8 to 5.9 years. Descriptive information on study participants and MetS components is presented in Table 1. Compared with participants who did not develop MetS, participants who developed MetS were older, reported a lower household income, and resided in areas with a lower income and a lower percentage of university graduates. Prevalence of MetS components at baseline was also higher in participants who developed MetS.

Regarding area-level SEP characteristics, the median of median household weekly income was 612 AUD (ranging from 361 to 1,323 AUD), and the median percentage of residents having a completed university education was $6.5 \%$ (ranging from 0 to $21.3 \%$ ) (Table 1 ).

\section{Area-level SEP and MetS incidence}

A total of 156 men (18.7\%) and 153 women (13.1\%) (15.6\% of the study sample) developed MetS. As presented in Table 2, there was an inverse association between area-level education and the risk of MetS: each unit increase in the percentage of residents with a university qualification corresponded to a $2 \%$ lower risk of developing MetS (Model 1: $\mathrm{RR}=0.98 ; 95 \% \mathrm{CI}=0.97$ 0.99). The statistical significance of this relationship was maintained following adjustments for individual-level SEP (Model 2), health risk behaviours (Model 3), and area-level income (Model 4). There was no statistical evidence $(p \geq 0.32)$ for an interaction between area-level education and either of the two individual-level SEP variables. Individual-level covariates beyond age and gender were not significantly associated with incident MetS.

Table 3 summarises the results of statistical models assessing the effects of area-level income. All four models indicated no statistical evidence $(p \geq 0.15)$ for an association between area-level median household weekly income and the presence of MetS at the Wave 2 follow up. However, there was a statistically significant interaction $(p=0.005)$ between individual- and area-level income, but no evidence for an interaction between arealevel income and individual-level education $(p=0.55)$. Among covariates other than age and gender, individual household income was significantly associated with incident MetS with the highest income participants having a $32 \%$ lower risk of developing MetS compared to those in the lowest income group (Full model: $\mathrm{RR}=0.68$; $95 \% \mathrm{CI}=$ $0.48-0.97)$. In all statistical models, there was no statistical evidence of an interaction between gender and any of area-level SEP measures $(p \geq 0.12)$. 
Table 1 Baseline characteristics of study participants by MetS status at Wave 2

\begin{tabular}{|c|c|c|c|}
\hline Characteristic & $\begin{array}{l}\text { Wave } 1 \text { MetS free }(n=1877) \\
\text { Median }(s d) / n \text { (percent) }\end{array}$ & $\begin{array}{l}\text { Not developing MetS }(n=1585) \\
\text { Median }(s d) / n \text { (percent) }\end{array}$ & $\begin{array}{l}\text { Developing MetS }(n=292) \\
\text { Median }(s d) / n \text { (percent) }\end{array}$ \\
\hline Age (years) & $47(15.5)$ & $45(15.5)$ & $55(14.7)$ \\
\hline \multicolumn{4}{|l|}{ Gender } \\
\hline Male & $816(43.5)$ & $663(41.8)$ & $153(52.4)$ \\
\hline Female & $1,061(56.5)$ & $922(58.2)$ & $139(47.6)$ \\
\hline \multicolumn{4}{|l|}{ Gross annual household income } \\
\hline$<20,000$ AUD & $538(28.7)$ & $447(28.2)$ & $91(31.2)$ \\
\hline 20,000-60,000 AUD & $913(48.6)$ & $765(43.8)$ & $148(50.7)$ \\
\hline$>60,000$ AUD & $426(22.7)$ & $373(23.5)$ & $53(18.1)$ \\
\hline \multicolumn{4}{|l|}{ Individual education } \\
\hline Bachelor degree (Yes) & $230(12.2)$ & $1,390(87.7)$ & $257(88.0)$ \\
\hline Bachelor degree (No) & $1,647(87.8)$ & $195(12.3)$ & $35(12.0)$ \\
\hline \multicolumn{4}{|l|}{ Physical Activity } \\
\hline Sedentary & $524(27.9)$ & $440(27.8)$ & $84(28.8)$ \\
\hline Low exercise & 669 (35.6) & $577(36.4)$ & $92(31.6)$ \\
\hline Moderate exercise & $515(27.4)$ & $435(27.4)$ & $80(27.4)$ \\
\hline High exercise & $169(9.0)$ & $133(8.4)$ & $36(12.3)$ \\
\hline \multicolumn{4}{|l|}{ Smoking* } \\
\hline Current & $344(18.3)$ & $287(18.1)$ & $57(19.5)$ \\
\hline Former & $669(37.2)$ & $661(38.6)$ & $88(30.1)$ \\
\hline Never & $834(44.4)$ & $687(43.3)$ & $147(50.3)$ \\
\hline \multicolumn{4}{|l|}{ Drinking } \\
\hline Not at risk & $1,325(70.6)$ & $1,112(70.2)$ & $213(73.0)$ \\
\hline At risk & $552(29.4$ & $473(29.8)$ & $79(27.0)$ \\
\hline \multicolumn{4}{|l|}{ Area-level SEP } \\
\hline Percent university education or more & $6.7(4.8)$ & $6.5(4.7)$ & $6.7(4.8)$ \\
\hline Median household weekly income (AUD) & $671(153)$ & $673(148)$ & $660(155)$ \\
\hline \multicolumn{4}{|l|}{ MetS component } \\
\hline Central obesity & $884(47.1)$ & $671(42.33)$ & $213(73.0)$ \\
\hline Low HDL cholesterol & $257(12.7)$ & $194(12.2)$ & $63(21.58)$ \\
\hline Hyperglycaemia & $150(8.0)$ & $122(7.7)$ & $28(9.6)$ \\
\hline Hypertriglyceridemia & $254(13.5)$ & $188(11.9)$ & $66(22.6)$ \\
\hline Hypertension & 673 (35.9) & $561(34.2)$ & $112(47.66)$ \\
\hline
\end{tabular}

To depict the nature of the interaction between areaand individual-level income, we conducted an analysis stratified according to individual household income (Table 3). A statistically significant association between area-level income and MetS incidence was observed for the high income participants. Specifically, a one standard deviation increase in area-level median household weekly income corresponded to a $31 \%$ higher risk of developing MetS (Model 1: RR = 1.31; 95\%CI = 1.07-1.62) in this group. The association persisted despite controlling for health behaviours (Model 3: $\mathrm{RR}=1.29 ; 95 \% \mathrm{CI}=$ 1.04-1.60), and area-level education (Model 4: $\mathrm{RR}=$
1.30; $95 \% \mathrm{CI}=1.05-1.62)$. In the lowest income group, having a bachelor's degree was significantly associated with a 2.73 times higher risk of developing MetS (Model $4: \mathrm{RR}=2.73 ; 95 \% \mathrm{CI}=1.23-6.06)$.

\section{Discussion}

As far as we are aware, this is the first longitudinal study to document a relationship between area-level SEP (measured as education and income) and incident MetS. In this welldefined Australian cohort, incident MetS occurred in $18.7 \%$ of men and $13.1 \%$ of women after an average of 3.6 years follow up. These data are comparable to similar 
Table 2 Association between area-level university education/income and MetS incidence $(n=1877)$

\begin{tabular}{|c|c|c|c|c|}
\hline & $\begin{array}{l}\text { Model } 1 \\
\text { RR }(95 \% \mathrm{Cl})\end{array}$ & $\begin{array}{l}\text { Model } 2 \\
\text { RR }(95 \% \mathrm{Cl})\end{array}$ & $\begin{array}{l}\text { Model } 3 \\
\text { RR }(95 \% \mathrm{Cl})\end{array}$ & $\begin{array}{l}\text { Model } 4 \\
\text { RR }(95 \% \mathrm{Cl})\end{array}$ \\
\hline \multicolumn{5}{|l|}{ Area-level education } \\
\hline Percent uni. education or more (per 1\% increase) & $0.98(0.97-0.99)^{\mathrm{a}}$ & $0.98(0.96-0.99)^{a}$ & $0.98(0.96-0.99)^{a}$ & $0.98(0.96-0.99)^{a}$ \\
\hline \multicolumn{5}{|l|}{ Annual household income } \\
\hline$<20,000$ AUD & - & Ref & Ref & \\
\hline $20,000-60,000$ AUD & - & $1.04(0.86-1.26)$ & $1.00(0.82-1.21)$ & $1.00(0.82-1.21)$ \\
\hline$>60,000$ AUD & - & $0.77(0.55-1.08)$ & $0.76(0.54-1.08)$ & $0.76(0.54-1.07)$ \\
\hline \multicolumn{5}{|l|}{ Individual education } \\
\hline Bachelor degree (No) & - & Ref & Ref & \\
\hline Bachelor degree (Yes) & - & $1.28(0.91-1.80)$ & $1.23(0.86-1.77)$ & $1.24(0.87-1.78)$ \\
\hline \multicolumn{5}{|l|}{ Area-level income } \\
\hline Median household weekly income (per 1 sd increase) & $0.97(0.88-1.07)$ & $0.89(0.75-1.07)$ & $0.88(0.74-1.05)$ & $0.93(0.78-1.10)$ \\
\hline \multicolumn{5}{|l|}{ Annual household income } \\
\hline$<20,000$ AUD & - & Ref & Ref & \\
\hline 20,000-40,000 AUD & - & $1.08(0.88-1.32)$ & $1.03(0.85-1.26)$ & $1.03(0.84-1.25)$ \\
\hline$>60,000$ AUD & - & $0.69(0.49-0.98)^{a}$ & $0.68(0.48-0.97)^{a}$ & $0.69(0.49-0.98)^{a}$ \\
\hline Area-level income $x$ Middle & - & $1.04(0.84-1.28)$ & $1.04(0.84-1.28)^{a}$ & $1.02(0.83-1.25)$ \\
\hline Area-level x High & - & $1.46(1.11-1.91)^{b}$ & $1.47(1.12-1.92)^{b}$ & $1.42(1.01-1.85)^{b}$ \\
\hline \multicolumn{5}{|l|}{ Individual education } \\
\hline Bachelor degree (No) & - & Ref & Ref & Ref \\
\hline Bachelor degree (Yes) & - & $1.20(0.86-1.66)$ & $1.15(0.81-1.64)$ & $1.21(0.85-1.74)$ \\
\hline
\end{tabular}

${ }^{\mathrm{a}} p<0.05 ;{ }^{\mathrm{b}} p<0.01$.

Model 1: Adjusted for age and gender.

Model 2: Adjusted for age and gender, and individual SEP.

Model 3: Adjusted for all variables in model 2 plus physical activity, smoking habit, and alcohol consumption.

Model 4: Adjusted for all variables in model 2 plus area-level income (for area-level education) or area-level education (for area-level income).

statistics in other western countries (e.g., United States (US) $[61,62])$, but higher than in some Asian populations (e.g., Korean [63], Japan [64], or Taiwan [65]), though incidence estimates are subject to different definitions of MetS [66]. Area-level education was independently and inversely associated with the incident MetS. Men and women living in areas where a greater proportion of the population complete a university education, independent of their own income, education, and health risk behaviours, were significantly less likely to develop MetS than their counterparts in areas where a lower proportion of the population obtain this level of education. The association between area-level income and the incident MetS, on the other hand, was modified by individual-level income in which a statistically significant association was only observed for the high income participants. These component-specific findings highlight the importance of investigating separate effects of specific features of the area-level SEP on the occurrence of MetS.

Our observation of a relationship between area-level education and incident MetS is plausible and consistent with the results of earlier studies investigating cardiometabolic risk factors. Higher neighbourhood education, for example, has in past studies been reported to be significantly associated with lower body mass index (BMI), and a lower prevalence of overweight/obesity [67], and hypertension [68]. The absence of a statistically significant association with individual-level income and education in multivariate regression models suggests that the ability of area-level education to predict incident MetS was robust, over and above the predictive ability of individuallevel SEP. With each percentage change in the proportion of individuals with a university education resulting in a $2 \%$ difference in the risk of acquiring MetS, socioeconomic disparities in the development of MetS could be substantial, given the marked differentials in the distribution of population with university education across Suburbs in the study region (i.e., from $0 \%$ to $21 \%$ of the population).

Several mechanisms can be proposed to explain the protective effect of area-level education on the incidence of MetS. First, a greater proportion of individuals with a higher level of education in communities can be plausibly linked to uptake of rapid dissemination of health education messages regarding cardiometabolic health such as healthy dietary behaviours and physical activity, both protective against metabolic disorders and the MetS. It is likely that such protective behaviours are 
Table 3 Association between area-level income and MetS incidence according to individual-level income

\begin{tabular}{|c|c|c|c|}
\hline & $<20,00$ AUD & $20,000-60,00$ AUD & $>60,000$ AUD \\
\hline & $\operatorname{RR}(95 \% \mathrm{Cl})(n=538)$ & $\operatorname{RR}(95 \% C l)(n=913)$ & $\operatorname{RR}(95 \% \mathrm{Cl})(n=426)$ \\
\hline \multicolumn{4}{|l|}{ Model 1} \\
\hline Median household weekly income (per 1 sd increase) & $0.90(0.75-1.08)$ & $0.92(0.82-1.03)$ & $1.31(1.07-1.62)^{a}$ \\
\hline \multicolumn{4}{|l|}{ Model 2} \\
\hline Median household weekly income (per 1 sd increase) & $0.87(0.72-1.05)$ & $0.92(0.81-1.05)$ & $1.31(1.05-1.62)^{\mathrm{a}}$ \\
\hline \multicolumn{4}{|l|}{ Individual-level education } \\
\hline \multicolumn{4}{|l|}{ Bachelor degree (No) } \\
\hline Bachelor degree (Yes) & $2.27(1.08-4.80)^{a}$ & $0.96(1.57-1.62)$ & $1.18(0.71-1.96)$ \\
\hline \multicolumn{4}{|l|}{ Model 3} \\
\hline Median household weekly income (per 1 sd increase) & $0.88(0.73-1.05)$ & $0.91(0.80-1.04)$ & $1.29(1.04-1.60)^{a}$ \\
\hline \multicolumn{4}{|l|}{ Individual-level education } \\
\hline \multicolumn{4}{|l|}{ Bachelor degree (No) } \\
\hline Bachelor degree (Yes) & $2.54(1.19-5.43)^{a}$ & $0.94(0.55-1.62)$ & $0.94(0.56-1.59)$ \\
\hline \multicolumn{4}{|l|}{ Model 4} \\
\hline Median household weekly income (per 1 sd increase) & $0.92(0.78-1.10)$ & $0.98(0.95-1.00)$ & $1.30(1.05-1.62)^{\mathrm{a}}$ \\
\hline \multicolumn{4}{|l|}{ Individual-level education } \\
\hline Bachelor degree (No) & Ref & Ref & Ref \\
\hline Bachelor degree (Yes) & $2.73(1.23-6.06)^{a}$ & $1.05(0.61-1.81)$ & $0.96(0.57-1.61)$ \\
\hline
\end{tabular}

${ }^{a} p<0.05$

Model 1: Adjusted for age and gender.

Model 2: Adjusted for age and gender, and individual SEP.

Model 3: Adjusted for all variables in model 2 plus physical activity, smoking habit, and alcohol consumption.

Model 4: Adjusted for all variables in model 2 plus area-level income (for area-level education) or area-level education (for area-level income).

quickly diffused throughout communities where a large proportion of residents have a higher level of education, leading to the establishment of social norms affecting health behaviours of even the less educated in these communities. Second, it is possible that communities with greater proportions of highly educated individuals are more aware of the impact of the residential environment on their health and thus are able to invest additional resources to establish and/or maintain a healthful living environment. Complementary literature indicates that neighbourhood education is positively associated with greater neighbourhood walkability [68] and availability of healthy foods $[68,69]$, which in turn, can encourage physical activity and healthy diet. Third, it has been postulated that highly educated individuals, who often have a high level of health literacy, tend to cluster in areas with advantaged social environments. For instance, earlier studies have reported a positive association between neighbourhood education and greater neighbourhood safety and social cohesion (e.g., [68]). As a result, the sources of chronic stress (e.g., poor social cohesion, violence, or crime) that induce metabolic abnormalities and MetS through endocrine pathways $[46,70,71]$ would be less likely to occur in communities where a greater proportion of local residents achieve a high level of education.
In examining the relationships between area-level income and the incident MetS, no statistically significant association was found in models involving the entire sample. For the highest income participants, however, area-level income was positively, rather than negatively, associated with the occurrence of MetS. Such findings were not supportive of the proposed hypotheses and mirror the current debate on the relationship between income and health, with some arguing that area-level income is not associated with individual health outcomes [72-74]. However the counterintuitive finding as seen in the high-income participants is not without precedent. In a US-based study, for example, a positive association between neighbourhood socioeconomic advantage and a worsening insulin resistance syndrome profile was reported for black men, but not for other ethnic groups [46]. In another study, arealevel income was not significantly associated with BMI in black men and black women, while a higher individuallevel income was positively associated with increased BMI in white men and black men [75]. Furthermore, it is worth commenting that a greater risk of MetS in low income people with an university education as found in our analysis could also reflect the effect of status discrepancy [76]. In highly educated individuals who earned a low income, there may be inner conflict over a sense of self-worth that drives undue actions and negative biological responses, 
leading to the increased risk for the MetS. However, this finding should be interpreted with caution given the small sample involved in the analysis and possible misreport of individual-level incomes that often occur in surveys [77].

The study has several important strengths. First, it is the first study using a longitudinal design to examine the role of area-level SEP in shaping the development of MetS in an Australian population. The observed associations, therefore, were not affected by the influence of prevalence-incidence bias and the potential for reverse causation as experienced by previous studies that relied on cross-sectional data. Second, the study overcomes shortcomings associated with the use of composite measures to rate the area-level SEP, unravelling relationships to assess the independent effect of area-level education and income on the development of MetS. Moreover, the analysis also included evaluation of individual- and arealevel SEP interactive effects on the occurrence of MetS. Finally, important confounding factors (e.g., health risk behaviours) were taken into account in the analyses.

Our study is not without limitations. First, 23\% loss to follow up might have caused selection bias. However, in a post-hoc analysis, the Wave 2 sample was similar to the baseline sample with respects to frequency distributions of participants' baseline characteristics: age, sex, household income, education, and behaviours (i.e., smoking, alcohol consumption, and physical activity). Furthermore, the low participation rate among the eligible population may have also engendered selection bias. However, in a published analysis conducted after baseline recruitment to examine the cohort participants in comparison with the eligible population, it was reported that there were no major differences in terms of cardiometabolic behavioural and biological risk factors (i.e., current smoking status, physical activity, BMI, hypertension, blood cholesterol level), though study participants were more likely to be in the middle level of household income and education attainment (i.e., finishing high school) [78]. Second, socioeconomic characteristics under the study were limited to income and education, which may not capture fully the multi-faceted nature of SEP. Third, area- and individuallevel socioeconomic characteristics were only measured at baseline, which was not representative of lifetime socioeconomic conditions. Furthermore, possible change to neighbourhood and individual SEP during the follow up period that also influences cardiometabolic health [79] was not accounted for in analysis. Similarly, area-level SEP measures were not updated for those who moved to a new residential area prior to the second clinical examination. As a result, assessment of area-SEP for these participants may not be entirely accurate, potentially causing some bias in the observed relationships. However, as we found that only $16 \%$ of the entire sample had changed their residential location, the effect of bias, if present, is likely to be minimal.
Fourth, as individuals can enter and exit the definition of MetS in a given time period (e.g., one year) depending on changes in levels of its clinical components [80], there is a possibility that in assessing the incident MetS, the current study has missed participants who developed MetS and then reversed prior to their second clinic visit, particularly those with a long interval between the two visits (e.g., >five years). This shortcoming may have resulted in an underestimate (not an overestimate) of the true MetS incidence and strength of its relationships with area-level SEP characteristics. Fourth, in examining associations between area- level income and the MetS incidence, stratified analysis was subject to small sample sizes and was therefore potentially under-powered to detect a significant association in low and middle income groups, while the presence of a significant association in the high income group may possibly be due to chance. Finally, the findings are potentially susceptible to the modifiable area unit problem, whereby the analytical results are sensitive to the definition of the spatial unit employed [81]. For example in this study, the operationalisation of area-level SEP at the State Suburb and reported associations with MetS incidence may be reflective of the underlying spatial properties (i.e., level of aggregation and configuration of zoning).

\section{Conclusions}

The results of this study support that area-level SEP can operate both independently and interactively with individual-level socioeconomic factors to influence the risk of developing MetS. Higher area-level education appeared to be plausibly and persistently associated with a lower risk for developing MetS, and therefore can present a marker of a healthful living environment protecting individuals, even the less individually educated, from acquiring MetS. In future public health interventions, special efforts are required to improve area-level environments and resources to facilitate healthy lifestyle and behaviours in communities where a large proportion of local residents are less educated in order to address socioeconomic disparities in the distribution and development of MetS. Findings on the relationship between area-level income and the MetS incidence, on the other hand, were counterintuitive and may be context-specific and therefore should be further examined in future studies.

To better delineate relationships between area-level SEP and the incidence of MetS, future studies should expand investigation to evaluating the effect of other arealevel SEP characteristics (e.g., occupational composition, employment status). A larger sample size will be needed to provide statistical power sufficient to assess effects across different individual SEP strata when evidence for interaction is present. In addition, regular clinical assessments 
during follow up are required to avoid the possibility for underreporting of incident MetS and better evaluate its relationships with area-level SEP. To understand mechanisms through which area-level SEP influences cardiometabolic risk factors and MetS, further studies are also needed to assess the role of other environmental factors such as built, social, or service environments in the risk of acquiring MetS. Together with the current study, findings from future studies will be valuable in guiding evidence-based health policy and public health interventions to reduce cardiometabolic risk factors and prevent the occurrence of MetS, and as a result reducing the risk for subsequent cardiometabolic diseases.

\section{Additional files}

Additional file 1: NWAH Study - Stage 1 CATI/QPL Telephone
Recruitment Questionnaire.
Additional file 2: QUESTIONNAIRE A. Stage 1 - Phase 1A \& Phase 1B.
Additional file 3: CATI RECRUITMENT QUESTIONNAIRE. NWAH
STUDY STAGE 2. From 7 June 2004.
Additional file 4: Questionnaire B. NWAH Study 2 - 04/05.

\section{Abbreviations}

ABS: Australian Bureau of Statistics; AUD: Australian dollar; BMI: Body mass index; CATI: Computer-assisted interview; Cl: Confidence interval; CHD: Coronary heart disease; GEE: Generalised estimating equations; HDL: High-density lipoprotein; MetS: Metabolic syndrome; NWAHS: North West Adelaide Health Study; PAMS: Place and metabolic syndrome; RR: Incidence risk ratio; SA: South Australia; SEP: Socioeconomic position; SSC: State suburb; sd: Standard deviation.

\section{Competing interests}

The authors declare that they have no competing interests.

\section{Authors' contributions}

$A N, C P$ and $M D$ contributed to the conception and design of the study. AT and RA were responsible for the collection of the North West Adelaide Health Study data, and provided the data for analysis. CP and NH managed and created individual-level measures. NC and NH undertook extractions of geospatial information. AN undertook the data analysis and drafted the manuscript. $\mathrm{AN}, \mathrm{CP}, \mathrm{NH}, \mathrm{NC}$, and $\mathrm{MD}$ contributed to interpretation of the results. All authors provided critical insight, and revisions to the manuscript. All authors read and approved the final version of the manuscript submitted for publication.

\section{Acknowledgements}

The Social Epidemiology and Evaluation Research Group at the University of South Australia in collaboration with the South Australian Department of Health conducted this research under National Health and Medical Research Council (NHMRC) grants \#631917 and \#570150 (Chief Investigators: Mark Daniel, Graeme Hugo, Catherine Paquet, Robert Adams, Anne Taylor, and Margaret Cargo). Catherine Paquet was funded by a NHMRC Post-doctoral Training Research Fellowship (\#570139).

This manuscript has been reviewed for scientific content and consistency of data interpretation by Chief Investigators of the North West Adelaide Health Study (NWAHS). We are grateful for the interest and commitment of cohort participants. We appreciate the contributions of research support staff involved in recruitment and clinical follow up.

\section{Author details}

${ }^{1}$ Social Epidemiology and Evaluation Research Group, Sansom Institute for Health Research, and School of Population Health, University of South Australia, Adelaide 5001, Australia. ${ }^{2}$ Research Centre of the Douglas Mental Health University Institute, Verdun, Québec H4H 1R2, Canada. ${ }^{3}$ The Health Observatory, Discipline of Medicine, The University of Adelaide, Adelaide,
South Australia 5005, Australia. ${ }^{4}$ Population Research and Outcome Studies, Discipline of Medicine, The University of Adelaide, Adelaide, South Australia 5005, Australia. ${ }^{5}$ Department of Medicine, The University of Melbourne, St Vincent's Hospital, Melbourne, Victoria 3065, Australia. 'Social Epidemiology and Evaluation Research Group, Sansom Institute for Health Research, and School of Population Health, University of South Australia, P4-18F, Playford Building, City East Campus, Adelaide 5000, Australia.

Received: 18 January 2013 Accepted: 19 July 2013

Published: 25 July 2013

\section{References}

1. Lisabeth JD: Neighbourhood environment and risk of ischemic stroke. Am J Epidemiol 2007, 165:279-287.

2. Diez Roux AV, Merkin SS, Arnett D, Chambless L, Massing M, Nieto FJ, Sorlie P, Szklo M, Tyroler HA, Watson RL: Neighborhood of residence and incidence of coronary heart disease. N Engl J Med 2001, 345(2):99-106.

3. Barker DJP, Gardner MJ, Power C: Incidence of diabetes amongst people aged 18-50 years in nine British Towns: a collaborative study. Diabetologia 1982, 22(6):421-425.

4. Krishnan S, Cozier YC, Rosenberg L, Palmer JR: Socioeconomic status and incidence of type 2 diabetes: results from the black women's health study. Am J Epidemiol 2010, 171(5):564-570.

5. House JS: Understanding social factors and inequalities in health: 20th century progress and 21st century prospects. J Heal Soc Behav 2002, 43(2):125-142

6. Link BG, Phelan JC, Miech R, Westin EL: The resources that matter: fundamental social causes of health disparities and the challenge of intelligence. J Heal Soc Behav 2008, 49(1):72-91.

7. Phelan JC, Link BG, Tehranifar P: Social conditions as fundamental causes of health inequalities: theory, evidence, and policy implications. I Heal Soc Behav 2010, 51(Suppl):S28-S40.

8. Kavanagh A, Bentley RJ, Turrell G, Shaw J, Dunstan D, Subramanian SV: Socioeconomic position, gender, health behaviours and biomarkers of cardiovascular disease and diabetes. Soc Sci Med 2010, 71(6):1150-1160.

9. Daniel M, Lekkas P, Cargo M, Stankov I, Brown A: Environmental risk conditions and pathways to cardiometabolic diseases in indigenous populations. Annu Rev Public Health 2011, 32:327-347.

10. Daniel $M$, Moore $S$, Kestens Y: Framing the biosocial pathways underlying associations between place and cardiometabolic disease. Health Place 2008, 14(2):117-132.

11. Diez-Roux AV, Nieto FJ, Muntaner C, Tyroler HA, Comstock GW, Shahar E, Cooper LS, Watson RL, Szklo M: Neighborhood environments and coronary heart disease: a multilevel analysis. Am J Epidemiol 1997, 146(1):48-63.

12. Leal C, Chaix B: The influence of geographic life environments on cardiometabolic risk factors: a systematic review, a methodological assessment and a research agenda. Obes Rev 2011, 12(3):217-230.

13. Loucks EB, Magnusson KT, Cook S, Rehkopf DH, Ford ES, Berkman LF: Socioeconomic position and the metabolic syndrome in early, middle, and late life: evidence from NHANES 1999-2002. Ann Epidemiol 2007, 17(10):782-790.

14. Loucks EB, Rehkopf DH, Thurston RC, Kawachi I: Socioeconomic disparities in metabolic syndrome differ by gender: evidence from NHANES III. Ann Epidemiol 2007, 17(1):19-26.

15. Lucove JC, Kaufman JS, James SA: Association between adult and childhood socioeconomic status and prevalence of the metabolic syndrome in African Americans: the Pitt county study. Am J Public Health 2007, 97(2):234-236.

16. Park YW, Zhu S, Palaniappan L, Heshka S, Carnethon MR, Heymsfield SB: The metabolic syndrome: Prevalence and associated risk factor findings in the US population from the Third National Health and Nutrition Examination Survey, 1988-1994. Arch Intern Med 2003, 163(4):427-436.

17. Dallongeville J, Cottel D, Ferrières J, Arveiler D, Bingham A, Ruidavets JB, Haas $B$, Ducimetière P, Amouyel P: Household income is associated with the risk of metabolic syndrome in a sex-specific manner. Diabetes Care 2005, 28(2):409-415.

18. Kim MH, Kim MK, Choi BY, Shin YJ: Educational disparities in the metabolic syndrome in a rapidly changing society - The case of South Korea. Int J Epidemiol 2005, 34(6):1266-1273. 
19. Langenberg C, Kuh D, Wadsworth MEJ, Brunner E, Hardy R: Social circumstances and education: life course origins of social inequalities in metabolic risk in a prospective national birth cohort. Am J Public Health 2006, 96(12):2216-2221.

20. Park MJ, Yun KE, Lee GE, Cho HJ, Park HS: A cross-sectional study of socioeconomic status and the metabolic syndrome in Korean adults. Ann Epidemiol 2007, 17(4):320-326.

21. Perel $P$, Langenberg C, Ferrie J, Moser K, Brunner E, Marmot M: Household wealth and the metabolic syndrome in the Whitehall II study. Diabetes Care 2006, 29(12):2694-2700.

22. Santos AC, Ebrahim S, Barros H: Gender, socio-economic status and metabolic syndrome in middle-aged and old adults. BMC Publ Health 2008, 8:62.

23. Silventoinen $K$, Pankow J, Jousilahti $P, H u$ G, Toumilehto J: Educational inequalities in the metabolic syndrome and coronary heart disease among middle-aged men and women. Int J Epidemiol 2005, 34(2):327-334.

24. Alkerwi A, Donneau AF, Sauvageot N, Lair ML, Albert A, Guillaume M: Dietary, behavioural and socio-economic determinants of the metabolic syndrome among adults in Luxembourg: findings from the ORISCAVLUX study. Public Health Nutr 2012, 15(5):849-859.

25. Agyemang C, van Valkengoed I, Hosper K, Nicolaou M, van den Born BJ, Stronks K: Educational inequalities in metabolic syndrome vary by ethnic group: evidence from the SUNSET study. Int J Cardiol 2010, 141(3):266-274.

26. Yang $X$, Tao Q, Sun F, Zhan S: The impact of socioeconomic status on the incidence of metabolic syndrome in a Taiwanese health screening population. Int J Public Health 2012, 57(3):1-9.

27. Wamala SP, Wolk A, Orth-Gomér K: Determinants of obesity in relation to socioeconomic status among middle-aged Swedish women. Prev Med 1997, 26(5 I):734-744.

28. Sobal J, Stunkard AJ: Socioeconomic status and obesity: a review of the literature. Psychol Bull 1989, 105(2):260-275.

29. Dekkers JC, Podolsky RH, Treiber FA, Barbeau P, Gutin B, Snieder H: Development of general and central obesity from childhood into early adulthood in African American and European American males and females with a family history of cardiovascular disease. Am J Clin Nutr 2004, 79(4):661-668.

30. Cubbin C, Sundquist K, Ahlén H, Johansson SE, Winkleby MA, Sundquist J: Neighborhood deprivation and cardiovascular disease risk factors: protective and harmful effects. Scand J Public Health 2006, 34(3):228-237.

31. Choi BCK, Shi F: Risk factors for diabetes mellitus by age and sex: results of the national population health survey. Diabetologia 2001, 44(10):1221-1231.

32. Connolly V, Unwin N, Sherriff P, Bilous R, Kelly W: Diabetes prevalence and socioeconomic status: a population based study showing increased prevalence of type 2 diabetes mellitus in deprived areas. J Epidemiol Community Health 2000, 54(3):173-177.

33. Tang $M$, Chen $Y$, Krewski D: Gender-related differences in the association between socioeconomic status and self-reported diabetes. Int J Epidemiol 2003, 32(3):381-385.

34. Colhoun HM, Hemingway H, Poulter NR: Socio-economic status and blood pressure: an overview analysis. J Hum Hypertens 1998, 12(2):91-110.

35. Matthews KA, Kiefe Cl, Lewis CE, Liu K, Sidney S, Yunis C: Socioeconomic trajectories and incident hypertension in a biracial cohort of young adults. Hypertension 2002, 39(3):772-776.

36. Cubbin C, Hadden WC, Winkleby MA: Neighborhood context and cardiovascular disease risk factors: the contribution of material deprivation. Ethn Dis 2000, 11(4):687-700.

37. Auchincloss AH, Diez Roux AV, Brown DG, O'Meara ES, Raghunathan TE: Association of insulin resistance with distance to wealthy areas: the multi-ethnic study of atherosclerosis. Am J Epidemio/ 2007, 165(4):389-397.

38. Brennan SL, Henry MJ, Nicholson GC, Kotowicz MA, Pasco JA: Socioeconomic status and risk factors for obesity and metabolic disorders in a population-based sample of adult females. Prev Med 2009 49(2-3):165-171

39. McGrath JJ, Matthews KA, Brady SS: Individual versus neighborhood socioeconomic status and race as predictors of adolescent ambulatory blood pressure and heart rate. Soc Sci Med 2006, 63(6):1442-1453.

40. Dubowitz T, Ghosh-Dastidar M, Eibner C, Slaughter ME, Fernandes M, Whitsel EA, Bird CE, Jewell A, Margolis KL, Li W, et al: The women's health initiative: the food environment, neighborhood socioeconomic status, BMI, and blood pressure. Obesity 2012, 20(4):862-871.
41. Chaix B, Bean K, Leal C, Thomas F, Havard S, Evans D, Jego B, Pannier B: Individual/neighborhood social factors and blood pressure in the RECORD Cohort Study: which risk factors explain the associations? Hypertension 2010, 55(3):769-775.

42. Laraia BA, Karter AJ, Warton EM, Schillinger D, Moffet HH, Adler N: Place matters: neighborhood deprivation and cardiometabolic risk factors in the diabetes study of Northern California (DISTANCE). Soc Sci Med 2012, 74(7):1082-1090.

43. Diez-Roux AV, Link BG, Northridge ME: A multilevel analysis of income inequality and cardiovascular disease risk factors. Soc Sci Med 2000, 50(5):673-687.

44. Leal C, Bean K, Thomas F, Chaix B: Are associations between neighborhood socioeconomic characteristics and body mass index or waist circumference based on model extrapolations? Epidemiology 2011 22(5):694-703.

45. Chichlowska KL, Rose KM, Diez-Roux AV, Golden SH, McNeill AM, Heiss G: Individual and neighborhood socioeconomic status characteristics and prevalence of metabolic syndrome: the atherosclerosis risk in communities (ARIC) study. Psychosom Med 2008, 70(9):986-992.

46. Diez Roux AV, Jacobs DR, Kiefe Cl: Neighborhood characteristics and components of the insulin resistance syndrome in young adults: The Coronary Artery Risk Development in Young Adults (CARDIA) Study. Diabetes Care 2002, 25(11):1976-1982.

47. Murakami K, Sasaki S, Takahashi Y, Uenishi K: Neighborhood socioeconomic status in relation to dietary intake and insulin resistance syndrome in female Japanese dietetic students. Nutrition 2010, 26(5):508-514.

48. Leitão M, Martins IS: Prevalence and factors associated with metabolic syndrome in users of primary healthcare units in São Paulo - SP. Brazil. Rev Assoc Med Bras 2012, 58(1):60-69.

49. Stafford M, Marmot M: Neighbourhood deprivation and health: does it affect us all equally? Int J Epidemiol 2003, 32(3):357-366.

50. Grant JF, Taylor AW, Ruffin RE, Wilson DH, Phillips PJ, Adams RJ, Price K: Cohort Profile: The North West Adelaide Health Study (NWAHS). Int J Epidemiol 2009, 38(6):1479-1486.

51. Australian Bureau of Statistics: South Australia (SSC), usual resident profile: Table U01 usual resident characteristics, retrieved from CDATA 2011. Cat. no. 2004.0. Canberra: Australian Bureau of Statistics; 2001.

52. Hetzel D, Page A, Glover J, Tennant S: Inequality in South Australia - key determinants of wellbeing. Adelaide: Department of Health - Government of South Australia; 2004.

53. International Diabetes Federation: The IDF consensus worldwide definition of the metabolic syndrome. Brussels, Belgium: International Diabetes Federation; 2006.

54. Australian Bureau of Statistics: Statistical geography: volume 2 - census geographic areas, Australia, 2001. Cat. no. 2905.0. Canberra: Australian Bureau of Statistics; 2001

55. Australian Guidelines to Reduce Health Risks from Drinking Alcohol: Australian guidelines to reduce health risks from drinking alcohol. http://www. nhmrc.gov.au/_files_nhmrc/publications/attachments/ds10-alcohol.pdf.

56. Australian Bureau of Statistics: National health survey: Users' guide - electronic publication, 2007-08. Canberra: Australian Bureau of Statistics; 2009.

57. Ainsworth BE, Haskell WL, Whitt MC, Irwin ML, Swartz AM, Strath SJ, Leon AS: Compendium of physical activities: an update of activity codes and MET intensities. Med Sci Sports Exerc 2000, 32:S498-S516.

58. Corp S: Stata Statistical Software: Release 11. College Station, TX: Stata Corp LP; 2009

59. Twisk JWR, Twisk JWR: Dichotomous outcome variables. In Applied longitudinal data analysis for epidemiology: a practical guide. Edited by Twisk JWR. Cambridge: Cambridge University Press; 2003:131-136.

60. Hubbard AE, Ahern J, Fleischer NL, Laan MVD, Lippman SA, Jewell N, Bruckner T, Satariano WA: To GEE or not to GEE: comparing population average and mixed models for estimating the associations between neighborhood risk factors and health. Epidemiology 2010, 21(4):467-474

61. Scuteri A, Morrell CH, Najjar SS, Muller D, Andres R, Ferrucci L, Lakatta EG: Longitudinal paths to the metabolic syndrome: can the incidence of the metabolic syndrome be predicted? The Baltimore longitudinal study of aging. J Gerontol Series A Biol Sci Med Sci 2009, 64(5):590-598.

62. Ingelsson E, Pencina MJ, Tofler GH, Benjamin EJ, Lanier KJ, Jacques PF, Fox CS, Meigs JB, Levy D, Larson MG, et al: Multimarker approach to evaluate the incidence of the metabolic syndrome and longitudinal 
changes in metabolic risk factors: the Framingham offspring study. Circulation 2007, 116(9):984-992.

63. Sung KC, Seo MH, Rhee EJ, Wilson AM: Elevated fasting insulin predicts the future incidence of metabolic syndrome: a 5-year follow-up study. Cardiovasc Diabetol 2011, 10:108.

64. Otsuka T, Kawada T, Yanai M, Kitagawa Y, Kan H: Incidence of metabolic syndrome and associated lifestyle factors in a worksite male population. J Occup Health 2011, 53:78-86.

65. Yang FY, Wahlqvist ML, Lee MS: Body mass index (BMI) as a major factor in the incidence of the metabolic syndrome and its constituents in unaffected Taiwanese from 1998 to 2002. Asia Pac J Clin Nutr 2008, 17:339-351.

66. Grundy SM, Cleeman JI, Daniels SR, Donato KA, Eckel RH, Franklin BA, Gordon DJ, Krauss RM, Savage PJ, Smith SC Jr, et al: Diagnosis and management of the metabolic syndrome: An American Heart Association/National Heart, Lung, and Blood Institute scientific statement. Executive summary. Cardiol Rev 2005, 13(6):322-327.

67. Mowafi M, Khadr Z, Subramanian SV, Bennett G, Hill A, Kawachi I: Are neighborhood education levels associated with BMI among adults in Cairo, Egypt? Soc Sci Med 2011, 72:1274-1283.

68. Mujahid MS, Roux VD, Morenoff JD, Raghunathan TE, Cooper RS, Ni H, Shea S: Neighborhood characteristics and hypertension. Epidemiol 2008, 19(4):590-598.

69. Daniel M, Kestens Y, Paquet C: Demographic and urban form correlates of healthful and unhealthful food availability in Montréal. Canada. Can J Public Health 2009, 100(3):189-193.

70. Cozier YC, Palmer JR, Horton NJ, Fredman L, Wise LA, Rosenberg L: Relation between neighborhood median housing value and hypertension risk among black women in the United States. Am J Public Health 2007, 97(4):718-724

71. Glass TA, Rasmussen MD, Schwartz BS: Neighborhoods and obesity in older adults. The Baltimore memory study. Am J Prev Med 2006, 31(6):455-463.

72. Mackenbach JP: Income inequality and population health: evidence favouring a negative correlation between income inequality and life expectancy has disappeared. Br Med J 2002, 324(7328):1-2.

73. Mellor JM, Milyo J: Reexamining the evidence of an ecological association between income inequality and health. J Health Polit Policy Law 2001, 26(3):487-522.

74. Mellor JM, Milyo J: Income inequality and health status in the United States: evidence from the current population survey. J Hum Resour 2002, 37(3):510-539.

75. Chang WW, Christakis NA: Income inequality and weight status in US metropolitan areas. Soc Sci Med 2005, 61(1):83-96.

76. Treiman DJ: Status discrepancy and prejudice. AJS 1996, 71(6):651-664.

77. Moore JC, Stinson LL, Welniak EJ Jr: Income reporting in surveys: cognitive issues and measurement error (pp. 155-173). In Cognition and survey research. Edited by Sirken MG, Herrmann DJ, Schechter S, Schwarz N, Tanur JM, Ourangeau R. New York: Wiley; 1999:155-173.

78. Taylor AW, Dal Grande E, Gill T, Chittleborough CR, Wilson DH, Adams RJ, Grant JF, Phillips P, Ruffin RE: Do people with risky behaviours participate in biomedical cohort studies? BMC Public Health 2006, 6:11.

79. Ruel E, Robert SA: A model of racial residential history and its association with self-rated health and mortality among Black and white adults in the US. Sociol Spectr 2009, 29:443-466.

80. Schorr SG, Slooff CJ, Bruggeman R, Taxis K: The incidence of metabolic syndrome and its reversal in a cohort of schizophrenic patients followed for one year. J Psychiatr Res 2009, 43:1106-1111.

81. Fotheringham AS, Wong DSW: The modifiable areal unit problem in multivariate statistical analysis. Environ Plann 1991, A23(7):1025-1044.

doi:10.1186/1471-2458-13-681

Cite this article as: Ngo et al:: Area-level socioeconomic characteristics and incidence of metabolic syndrome: a prospective cohort study. BMC Public Health 2013 13:681.

\section{Submit your next manuscript to BioMed Central and take full advantage of:}

- Convenient online submission

- Thorough peer review

- No space constraints or color figure charges

- Immediate publication on acceptance

- Inclusion in PubMed, CAS, Scopus and Google Scholar

- Research which is freely available for redistribution

Submit your manuscript at www.biomedcentral.com/submit
C Biomed Central 